\title{
The risk of revision after total hip arthroplasty in young patients depends on surgical approach, femoral head size and bearing type; an analysis of 19,682 operations in the Dutch arthroplasty register
}

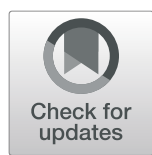

\author{
M. F. L. Kuijpers ${ }^{1 *} \mathbb{D}$, G. Hannink ${ }^{2}$, S. B. W. Vehmeijer ${ }^{3}$, L. N. van Steenbergen ${ }^{4}$ and B. W. Schreurs ${ }^{1}$
}

\begin{abstract}
Background: Total hip arthroplasty (THA) is used increasingly in younger patients. There is little knowledge about the effect of THA characteristics on risk of revision, especially in young patients. Therefore, we studied the influence of both patient-related and surgical factors on the risk of revision using data from the Dutch Arthroplasty Registry (LROI).

Methods: All patients younger than 55 years with a primary THA implanted in the Netherlands between 2007 and 2017 were selected $(n=19,682)$. The covariates age, sex, primary diagnosis, ASA-classification, surgical approach, fixation method, bearing type, head size and year of surgery were entered into Cox proportional hazards models to calculate hazard ratios for the risk of revision.

Results: The overall 5-year survival of primary THA was 95.3\% (95\% Cl, 94.9-95.6). Use of the anterior approach resulted in a lower risk of revision than the use of the posterolateral approach (HR: 0.66, 95\% Cl: 0.47-0.92). THAs with a head diameter $\geq 38 \mathrm{~mm}$ had a higher risk of revision (HR: 1.90, 95\% Cl: 1.33-2.72) than THAs with $32 \mathrm{~mm}$ heads. Use of MoM bearings resulted in an increased risk when compared to C-PE (HR: 1.76, 95\% Cl: 1.27-2.43).

Conclusion: The risk of revision in patients younger than 55 years depends on surgical approach, head size and bearing type. The anterior approach resulted in a decreased risk of revision, whereas use of $\geq 38 \mathrm{~mm}$ heads and MoM bearings resulted in an increased risk of revision for any reason.
\end{abstract}

Keywords: Total hip arthoplasty, Young patients, Registry, Risk of revision

\section{Background}

Total hip arthroplasty (THA) has shown to be a cost-effective treatment for osteoarthritis of the hip, with reported increase in quality of life, regained physical ability and reduction of pain $[1,2]$. THA is used increasingly in young patients, and this number will grow in the coming years. By the year 2030, it is estimated that more than $25 \%$ of all THA will be placed in patients under the age of 55 [3]. However, the outcome of THA in these young patients is inferior compared with older patients [4-6].

\footnotetext{
* Correspondence: martijn.kuijpers@radboudumc.nl

'Radboud university medical center, Radboud Institute for Health Sciences,

Department of Orthopaedics, Nijmegen, The Netherlands

Full list of author information is available at the end of the article
}

The main complications after THA include dislocation, infection, and loosening of the femoral or acetabular component. Young patients will outlive their prosthesis due to longer life expectancy, and survival at mid- and long-term is lower in patients younger than 55 years when compared with older patients [7].

Many studies reported factors that are associated with an increased risk of revision. For example, use of the posterolateral approach is associated with higher risks of revision due to dislocation and infection when compared with the anterior approach, and also resulted in more reoperations $[8,9]$. Also the use of larger head diameters is associated with a lower risk of revision, where heads larger than $28 \mathrm{~mm}$ have a lower risk when compared to

(c) The Author(s). 2019 Open Access This article is distributed under the terms of the Creative Commons Attribution 4.0 International License (http://creativecommons.org/licenses/by/4.0/), which permits unrestricted use, distribution, and reproduction in any medium, provided you give appropriate credit to the original author(s) and the source, provide a link to the Creative Commons license, and indicate if changes were made. The Creative Commons Public Domain Dedication waiver (http://creativecommons.org/publicdomain/zero/1.0/) applies to the data made available in this article, unless otherwise stated. 
heads smaller than $28 \mathrm{~mm}$ [10]. However, these studies were not specific for young patients and the sample size of the described studies was low.

Understanding of factors that are associated with early revisions is of major importance, not only to be able to reduce the risks of revision, but also to provide realistic expectations to this young patient group.

Therefore, we studied the influence of both patient-related and surgical factors on the risk of revision due to any reason using data from the Dutch Arthroplasty Register (LROI).

\section{Methods}

The LROI (Dutch Arthroplasty Registry) collects data about joint arthroplasties on a nationwide basis. Initiated by the Dutch Orthopaedic Association, data collection started in 2007. Coverage of all Dutch hospitals was reached in 2012. The database has a completeness of over $95 \%$ of primary THA and $88 \%$ for revision arthroplasty [11]. Patient characteristics are recorded at the moment of the primary procedure. Prostheses characteristics are derived from a implant library within the LROI, where all characteristics of prostheses used in the Netherlands are available [11].

For the present study, we included all patients younger than 55 years with a primary THA implanted in the Netherlands in the period between 2007 and 2017. Exclusion criteria were hip resurfacings, a surgical approach other than a posterolateral, anterior, direct lateral or anterolateral approach, and a bearing type other than ceramic-on-polyethylene (C-PE), metal-on-metal (MoM), ceramic-on-ceramic (CoC), metal-on-polyethylene (M-PE) and oxidised zirconium-on-polyethylene (Zr-PE).

\section{Statistics}

Continuous variables were described using means and standard deviations, or medians and interquartile ranges, where appropriate. Categorical data were described using count and percentages.

Kaplan-Meier survival analyses were used to determine the 5-year survival rate with end-point revision for any reason. Cox proportional hazards models were used to analyze the influence of various covariates on the hazard ration (HR) of revision for any reason. The covariates age, sex, ASA-classification (I, II, III-IV), primary diagnosis, head size $(22-26 \mathrm{~mm}, 28 \mathrm{~mm}, 32 \mathrm{~mm}, 36 \mathrm{~mm}$ and $\geq 38 \mathrm{~mm}$ ), fixation method, surgical approach, bearing type (C-PE, MoM, M-PE, CoC and $\mathrm{Zr}-\mathrm{PE}$ ) and period of surgery (2007-2011, 2012-2016) were initially investigated as single covariates resulting in a crude HR with 95\% CI with endpoint any reason. Primary diagnosis was dichotomized into primary osteoarthritis and secondary osteoarthritis. Secondary osteoarthritis results from a condition that changes the cartilage environment, including trauma, congenital or developmental joint abnormalities, metabolic defects and infection [12, 13]. Therefore, we included multiple diagnoses, such as dysplasia, osteonecrosis, (acute) fracture, inflammatory arthritis, late posttraumatic, post-Perthes and rheumatoid arthritis into secondary osteoarthritis. Multivariable Cox proportional hazard regression analyses were used to estimate adjusted HRs with 95\% CI for endpoint revision for any reason, while adjusting for all mentioned covariates. Due to low numbers of events, we decided not to calculate the risk of revision for other endpoints than any reason to prevent violation of the events per variable ratio [14]. The proportional hazard assumption was checked for all variables added to the Cox proportional hazard model. All analyses were performed using $\mathrm{R}$ version 3.2.4 (R Foundation for Statistical Computing, Vienna, Austria).

\section{Results}

Patient- and implant characteristics

Between January 1st, 2007 and December 31st, 2016, a total number of 19,682 THAs were registered in patients under 55 years in the LROI. Mean age was 47.1 years (SD 7.33), more THAs were placed in women (53.3\%). The most prevalent diagnosis was osteoarthritis $(66.2 \%)$, and almost half of patients were ASA I (48.3\%). Most THAs had an uncemented fixation $(79.8 \%, n=15,701)$, had a 32 $\mathrm{mm}$ head diameter $(41.5 \%, n=8165)$ and a C-PE bearing $(48.2 \%, n=9493)$. The posterolateral approach was used most frequently $(62.8 \%, n=12,367)$, followed by the direct lateral approach $(20.4 \%, n=4014)$, anterior approach $(10.4 \%, n=2053)$ and the anterolateral approach $(6.3 \%$, $n=1248)$. Patient- and implant characteristics are described in Table 1.

\section{Reasons for revisions}

The overall rate of revision was low. In total, there were 783 revisions 1 year after THA (3.98\%). The most common reason for revision was dislocation (22.5\%), followed by femoral loosening (18.0\%), infection (16.9\%) and acetabular loosening (14.9\%) (Table 2).

The overall survival of primary THA with end-point revision for any reason at 1, 2 and 5 years follow up was 98.3\% (95\% CI: 98.2-98.5), 97.3\% (95\% CI: 97.1-97.6) and $95.3 \%$ (95\% CI, 94.9-95.6), respectively.

\section{Unadjusted risk of revision for any reason}

In the unadjusted Cox regression, a decreased risk of revision for any reason for the anterior approach was found. Additionally, also the direct lateral approach was associated with a decreased risk of revision. Furthermore, head diameters of $28 \mathrm{~mm}$ and $\geq 38 \mathrm{~mm}$ were associated with a higher risk of revision when compared to a head diameter of $32 \mathrm{~mm}$. Finally, use of $\mathrm{CoC}$ as bearing 
Table 1 Patient and implant characteristics of 19,682 THA in patients younger than 55 years old

\begin{tabular}{|c|c|}
\hline & N (\%) \\
\hline Male & $9127(46.4)$ \\
\hline Age $(y)^{a}$ & $49.0(45.0-52.0)$ \\
\hline \multicolumn{2}{|l|}{ ASA-classification } \\
\hline ASA I & $9323(47.4)$ \\
\hline ASA $\|$ & $8371(42.5)$ \\
\hline ASA III-IV & $1368(7.0)$ \\
\hline \multicolumn{2}{|l|}{ Diagnosis } \\
\hline Primary osteoarthritis & $13,035(66.2)$ \\
\hline Secondary osteoarthritis & $6453(32.8)$ \\
\hline \multicolumn{2}{|l|}{ Fixation } \\
\hline Cemented & $1924(9.8)$ \\
\hline Uncemented & $15,701(79.8)$ \\
\hline Hybrid & $312(1.6)$ \\
\hline Reversed hybrid & $1614(8.2)$ \\
\hline \multicolumn{2}{|l|}{ Head Diameter } \\
\hline $22-26 \mathrm{~mm}$ & $163(0.8)$ \\
\hline $28 \mathrm{~mm}$ & $5600(28.5)$ \\
\hline $32 \mathrm{~mm}$ & 8165 (41.5) \\
\hline $36 \mathrm{~mm}$ & $4212(21.4)$ \\
\hline$\geq 38 \mathrm{~mm}$ & $750(3.8)$ \\
\hline \multicolumn{2}{|l|}{ Bearing type } \\
\hline C-PE & $9493(48.2)$ \\
\hline MoM & 899 (4.6) \\
\hline$M-P E$ & 3825 (19.4) \\
\hline $\mathrm{CoC}$ & $2701(13.7)$ \\
\hline Zr-PE & $1132(5.8)$ \\
\hline \multicolumn{2}{|l|}{ Surgical approach } \\
\hline Posterolateral & $12,367(62.8)$ \\
\hline Anterior & $2053(10.4)$ \\
\hline Direct lateral & $4014(20.4)$ \\
\hline Anterolateral & $1248(6.3)$ \\
\hline
\end{tabular}

${ }^{\mathrm{a} M e d i a n}(\mathrm{IQR})$

Table 2 Reason for revision as percentage of all revisions

\begin{tabular}{ll}
\hline Dislocation & $\mathrm{N}(\%)$ \\
Loosening femur & $176(22.5)$ \\
Infection & $141(18.0)$ \\
Loosening acetabulum & $132(17.5)$ \\
Periprosthetic fracture & $117(14.9)$ \\
Other & $49(6.3)$ \\
Total & $208(26.6)$ \\
\hline
\end{tabular}

The total is more than $100 \%$, as patients can have more than one reason for revision type resulted in a decreased risk of revision, where use of MoM resulted in a significant increased risk of revision (Table 3).

\section{Multivariable risk of revision for any reason}

The use of the anterior approach resulted in a decreased risk for revision after THA when compared with the posterolateral approach (HR: 0.66, 95\% CI: 0.47-0.92, $p=0.01$ ). THAs placed using the direct lateral (HR: 0.86 (95\% CI: $0.71-1.04, p=0.1)$ ) or anterolateral approach (HR: 1.16 (95\% CI: 0.89-1.52, $p=0.3$ )) had no significant different risk of revision compared to the posterolateral approach (Table 3, Fig. 1).

The use of head diameters $\geq 38 \mathrm{~mm}$ resulted in an increased risk of revision when compared to $32 \mathrm{~mm}$ heads (HR: 1.90 (95\% CI: 1.33-2.72, $p<0.001$ ), Fig. 2). Additionally, the use of MoM bearings had an increased the risk of revision (HR: 1.76 (95\% CI: 1.27-2.43, $p<0.001$ )).

\section{Discussion}

The aim of this paper was to assess the influence of both patient-related and surgical factors on the short-term risk of revision in young patients, using data from the LROI. After adjusting for patient- and THA characteristics, our analysis shows a significant decreased risk of revision for any reason for the anterior approach. The use of the direct lateral approach and the anterolateral approach resulted in a reduced risk of revision, however these findings were not significant.

In literature, there is limited evidence about the effect of surgical approach on the short term risk of revision in young patients. Recent reports, assessing the short-term complication rate between the anterior and posterolateral approach, found no significant difference in postoperative complication rate and risk of revision [15, 16]. Some reports claim a favourable outcome of the anterior approach over the posterolateral approach when looking at recovery time and stability of the hip [17-19]. However, these studies did not focus on young patients and concluded that more evidence was needed.

We found an increased short-term risk of revision with increasing head diameters, which is in line with literature and registry reports $[8,20,21]$. In literature, the use of small head diameters is associated with an increased risk of dislocation [22, 23]. When we look at the rate of revision for dislocation in our population, we can conclude that the overall rate is low. Only $0.89 \%$ of all THAs were revised for dislocation 5 year after procedure, which is comparable with literature [24]. Due to these low numbers, we were not able to determine the effect of patient- and surgical characteristics on the risk of revision due to dislocation as endpoint.

It might be possible that the lower risk of revision of the anterior approach disappears after a longer follow- 
Table 3 Risk of revision for any reason

\begin{tabular}{|c|c|c|c|}
\hline & Crude HR (95\% CI) & Adjusted HR $(95 \% \mathrm{Cl})^{\mathrm{a}}$ & $p$-value $^{b}$ \\
\hline \multicolumn{4}{|l|}{ Gender } \\
\hline Female & $1.02(0.89-1.16)$ & $1.09(0.94-1.26)$ & 0.27 \\
\hline Age & $1.00(0.99-1.01)$ & $1.00(0.99-1.01)$ & 0.9 \\
\hline \multicolumn{4}{|l|}{ Year of surgery } \\
\hline 2007-2011 & 1 & 1 & - \\
\hline 2012-2016 & $0.94(0.82-1.09)$ & $1.13(0.96-1.35)$ & 0.14 \\
\hline \multicolumn{4}{|l|}{ ASA-classification } \\
\hline ASA I & 1 & 1 & - \\
\hline ASA $\|$ & $0.98(0.85-1.13)$ & $1.00(0.85-1.16)$ & 0.9 \\
\hline ASA III-IV & $1.24(0.97-1.60)$ & $1.25(0.94-1.64)$ & 0.12 \\
\hline \multicolumn{4}{|l|}{ Diagnosis } \\
\hline Primary osteoarthritis & 1 & 1 & - \\
\hline Secondary osteoarthritis $^{c}$ & $1.04(0.91-1.20)$ & $0.95(0.81-1.12)$ & 0.55 \\
\hline \multicolumn{4}{|l|}{ Surgical approach } \\
\hline Posterolateral & 1 & 1 & - \\
\hline Anterior & $0.52(0.38-0.71)$ & $0.66(0.47-0.92)$ & 0.01 \\
\hline Direct lateral & $0.82(0.70-0.98)$ & $0.86(0.71-1.04)$ & 0.12 \\
\hline Anterolateral & $1.05(0.82-1.34)$ & $1.16(0.89-1.52)$ & 0.27 \\
\hline \multicolumn{4}{|l|}{ Fixation } \\
\hline Uncemented & 1 & 1 & - \\
\hline Cemented & $1.15(0.93-1.42)$ & $0.91(0.67-1.23)$ & 0.54 \\
\hline Hybrid & $1.24(0.75-2.08)$ & $1.32(0.74-2.35)$ & 0.35 \\
\hline Reversed hybrid & $1.21(0.96-1.52)$ & $1.19(0.91-1.55)$ & 0.22 \\
\hline \multicolumn{4}{|l|}{ Head Diameter } \\
\hline $32 \mathrm{~mm}$ & 1 & 1 & - \\
\hline $22-26 \mathrm{~mm}$ & $1.54(0.79-2.99)$ & $1.49(0.75-2.99)$ & 0.26 \\
\hline $28 \mathrm{~mm}$ & $1.21(1.03-1.43)$ & $1.11(0.92-1.34)$ & 0.28 \\
\hline $36 \mathrm{~mm}$ & $1.02(0.84-1.23)$ & $1.14(0.92-1.42)$ & 0.22 \\
\hline$\geq 38 \mathrm{~mm}$ & $2.85(2.27-3.57)$ & $1.90(1.33-2.72)$ & $<0.001$ \\
\hline \multicolumn{4}{|l|}{ Bearing type } \\
\hline C-PE & 1 & 1 & - \\
\hline MoM & 2.39 (1.94-2.94) & $1.76(1.27-2.43)$ & $<0.001$ \\
\hline$M-P E$ & $1.06(0.88-1.27)$ & $1.02(0.83-1.26)$ & 0.83 \\
\hline $\mathrm{CoC}$ & $0.77(0.61-0.97)$ & $0.77(0.60-1.00)$ & 0.05 \\
\hline $\mathrm{Zr}-\mathrm{PE}$ & $0.92(0.67-1.28)$ & $0.90(0.64-1.25)$ & 0.52 \\
\hline
\end{tabular}

${ }^{a}$ Multivariable Cox regression analysis performed with 17,288 observations and 741 events (complete cases); ${ }^{b} p$-value based on adjusted HR; ${ }^{{ }^{i n c l u d e s}}$ dysplasia, osteonecrosis, (acute) fracture, inflammatory arthritis, late posttraumatic, Post-Perthes and rheumatoid arthritis

up. Another study based on LROI data evaluated the effect of surgical approach in all ages. [25]. In contrast to the current finding, they found the highest risk of revision for any reason for the anterior approach, even after exclusion of the first 150 procedures of each centre that performed the anterior approach to correct for a possible learning curve. Also other studies did not found an effect of surgical approach on a longer term [9, 26]. However, because of a higher activity level in young patients, and the high burden of young patients needing a revision procedure, it is of interest to analyze the short-term risk of complications.

Lastly, we found an increased risk for revision for MoM bearings. These findings are described extensively 
Adjusted survival probability by surgical approach

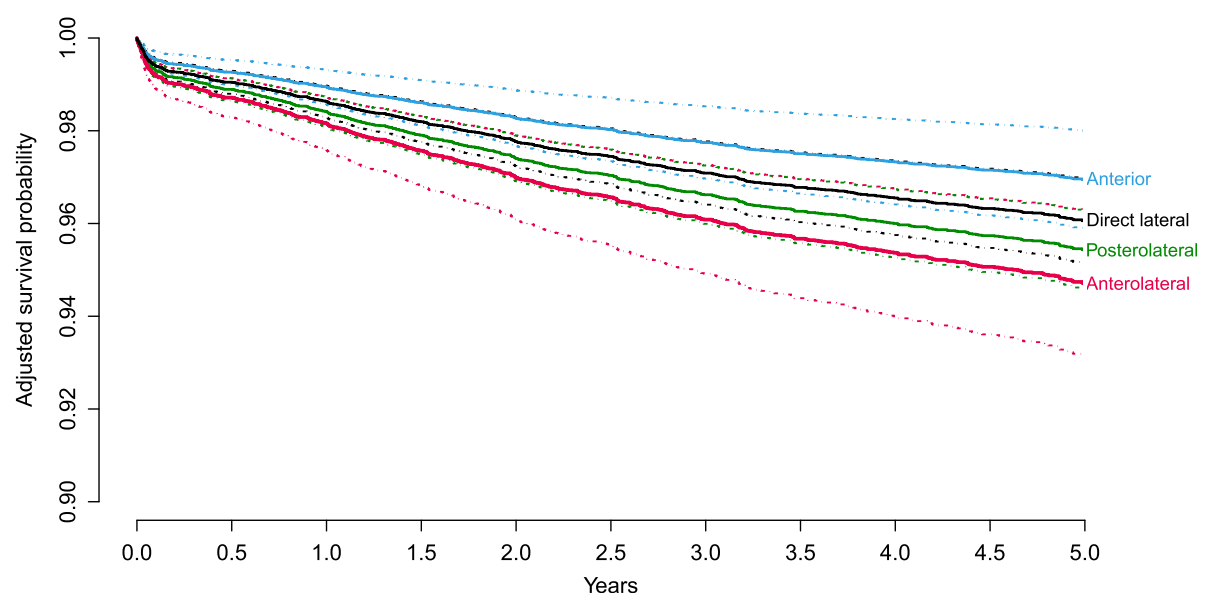

Fig. 1 Adjusted survival probability by surgical approach

in literature and registry reports [20, 21, 27]. The use of other bearings did not result in significant differences when compared to C-PE.

In our study, we found low numbers of reported periprosthetic fractures, especially in the anterior group. A possible explanation might be a better bone quality and flexibility in young patients, which can result in less fractures after THA. However, a second explanation can be due to underreporting of periprosthetic fractures in the registry, where a reoperation with no replacements of any of the components of the implant, is not registered as a revision. A similar explanation would apply to infections, where treatment of infection without replacement of any of the components is not reported as a revision for infection in the registry [28]. Therefore, the actual percentage of revision, due to periprosthetic fractures and infections, might be higher than reported in this paper.

Because of the increasing use of the anterior approach, the effect of a learning curve for this approach should be addressed. De Steiger et al. concluded that 50 or more procedures need to be performed before the rate of revision is no different from performing 100 or more procedures [29], where the most reduction in complication rate occurred after the first 100 THAs [30]. Out of 100 institutes in the Netherlands, 27 performed at least 5 or more THAs using the anterior approach. Therefore, it can be concluded that the possible effect of a learning curve is present in our data. Despite this possible effect, the rate of revision was still lower for the anterior approach, when compared to all other approaches.

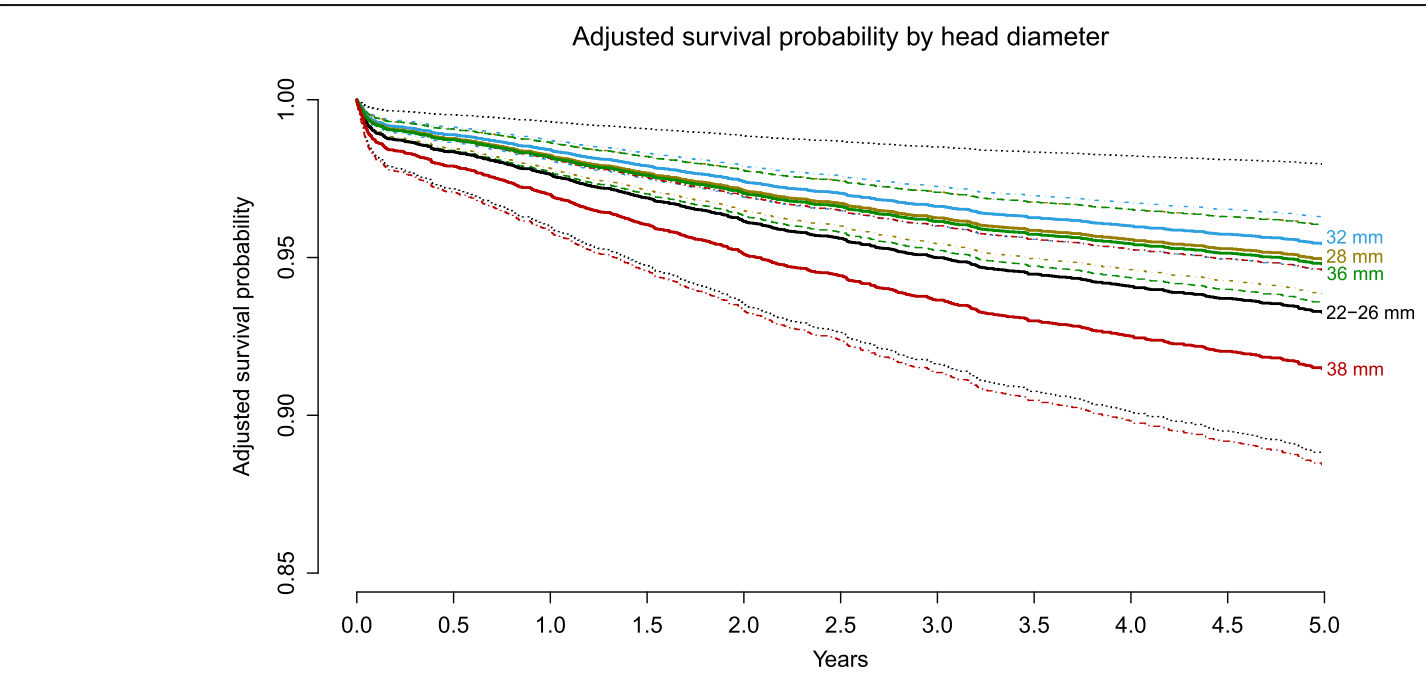

Fig. 2 Adjusted survival probability by head diameter 
This study has some potential limitations that have to be considered. First, the follow-up of this study was limited. The effect of patient- and THA characteristics on risk of revision can change when follow-up is increased to a long term. However, especially for this young patient group, risk of revision on a short term is of major interest. Second, in our analysis we were unable to adjust for some variables that measure the patient's demand on the implant, such as BMI and activity levels, as these were not, or only limited available from the Dutch Arthroplasty Register. Therefore, some residual confounding may be present. Lastly, we did not account for the possible effect of bilateral cases on the assumption of independence of observations in our statistical analysis. It has been shown that ignoring data dependency within a subject in studies involving bilateral cases may result in biased estimates [31, 32]. The extent of the resulting bias, however, was not determined in these studies.

Robertsson and Ranstam investigated if ignoring bilateral operations in statistical analyses biases the results, by analysing 55,298 prostheses in 44,590 patients using data from the Swedish Knee Arthroplasty Register [33]. They found that the effect of neglecting bilateral prostheses is minute, possibly because bilateral prosthesis failure is a rare event, and concluded that the revision risk of implants can be analysed without consideration for subject dependency, at least in study populations with a relatively low proportion of subjects having experienced bilateral revisions.

The percentage of bilateral implants in our cohort was $10.3 \%$, which is considerably lower than the proportion of bilateral implants in the study of Robertsson and Ranstam (19.4\%) [33]. Therefore, we think the possible effect of dependency between observations may be negligible in our analysis.

\section{Conclusions}

In conclusion, there is a significant reduced risk of revision in patients younger than 55 years when the anterior approach was used. The use of head diameters $\geq 38 \mathrm{~mm}$ resulted in an increased risk of revision when compared with $32 \mathrm{~mm}$ heads, whereas the use of MoM as bearing type had also an increased risk of revision. The effect of THA characteristics is rarely evaluated in this young patient group. Understanding of risk factors is necessary to prevent early revisions, and manage expectations of young patients.

\section{Abbreviations}

CoC: Ceramic-on-ceramic; C-PE: Ceramic-on-polyethylene; HR: Hazard ration; MoM: Metal-on-metal; M-PE: Metal-on-polyethylene; THA: Total hip arthroplasty; Zr-PE: Oxidised zirconium-on-polyethylene

\section{Acknowledgements}

We would like to thank the Van Rens Foundation for making this research possible.

\section{Authors' contribution}

Conception and Design: MFLK, GH, LNvS, BWS. Data analysis and interpretation: MFLK, GH, LNvS, BWS. Manuscript preparation: MFLK, GH, BWS. Manuscript editing: MFLK, GH, SBWV, LNvS, BWS. Manuscript review: MFLK, GH, SBWV, LNvS, BWS. Final approval of the version submitted: MFLK, GH, SBWV, LNvS, BWS.

\section{Funding}

This study was funded by the Van Rens Foundation (VRF2017-009), the Netherlands. The funding body had no role in the design of the study, data collection, analysis, and interpretation and in writing the manuscript.

\section{Availability of data and materials}

Data are available from the LROI (Dutch Arthroplasty Registry) but restrictions apply to the availability of these data, which were used under license for the current study.

Ethics approval and consent to participate

Not applicable, as all data was received completely anonymous.

Consent for publication

Not applicable.

\section{Competing interests}

The authors declare that they have no competing interests.

\section{Author details}

${ }^{1}$ Radboud university medical center, Radboud Institute for Health Sciences, Department of Orthopaedics, Nijmegen, The Netherlands. ${ }^{2}$ Radboud university medical center, Radboud Institute for Health Sciences, Department of Operating Rooms, Nijmegen, The Netherlands. ${ }^{3}$ Department of Orthopaedic Surgery, Reinier de Graaf Hospital, Delft, the Netherlands. ${ }^{4}$ Dutch Arthroplasty Register (Landelijke Registratie Orthopedische Implantaten), 's-Hertogenbosch, the Netherlands.

Received: 21 December 2018 Accepted: 15 August 2019

Published online: 22 August 2019

\section{References}

1. Learmonth ID, Young C, Rorabeck C. The operation of the century: total hip replacement. Lancet. 2007;370(9597):1508-19.

2. Shan L, Shan B, Graham D, Saxena A. Total hip replacement: a systematic review and meta-analysis on mid-term quality of life. Osteoarthr Cartil. 2014; 22(3):389-406.

3. Kurtz SM, Lau E, Ong K, Zhao K, Kelly M, Bozic KJ. Future young patient demand for primary and revision joint replacement: national projections from 2010 to 2030. Clin Orthop Relat Res. 2009;467(10):2606-12.

4. National Joint Registry for England W, Nothern Ireland and the Isle of Man: 13th Annaual report; 2016. Accessed on 08-Nov-2018. Available from: http:// www.njrreports.org.uk/Portals//PDDFdownloads/NJR\%2013th\%20Annual\%2 OReport\%202016.pdf

5. Schmitz M, Timmer C, Hannink G, Schreurs BW. Systematic review: lack of evidence for the success of revision arthroplasty outcome in younger patients. Hip Int. 2018;28(2):109-14.

6. Bayliss LE, Culliford D, Monk AP, Glyn-Jones S, Prieto-Alhambra D, Judge A, et al. The effect of patient age at intervention on risk of implant revision after total replacement of the hip or knee: a population-based cohort study. Lancet. 2017;389(10077):1424-30.

7. Lee PT, Lakstein DL, Lozano B, Safir O, Backstein J, Gross AE. Mid-to longterm results of revision total hip replacement in patients aged 50 years or younger. Bone Joint J. 2014;96-B(8):1047-51.

8. Miller LE, Gondusky JS, Kamath AF, Boettner F, Wright J, Bhattacharyya S. Influence of surgical approach on complication risk in primary total hip arthroplasty. Acta Orthop. 2018;89(3):289-94.

9. Sheth D, Cafri G, Inacio MC, Paxton EW, Namba RS. Anterior and anterolateral approaches for THA are associated with lower dislocation risk without higher revision risk. Clin Orthop Relat Res. 2015;473(11):3401-8.

10. Kostensalo I, Junnila M, Virolainen $P$, Remes V, Matilainen M, Vahlberg $T$, et al. Effect of femoral head size on risk of revision for dislocation after total hip arthroplasty: a population-based analysis of 42,379 primary procedures from the Finnish arthroplasty register. Acta Orthop. 2013;84(4):342-7. 
11. van Steenbergen LN, Denissen GA, Spooren A, van Rooden SM, van Oosterhout FJ, Morrenhof JW, et al. More than 95\% completeness of reported procedures in the population-based Dutch arthroplasty register. Acta Orthop. 2015:86(4):498-505.

12. Murphy NJ, Eyles JP, Hunter DJ. Hip osteoarthritis: Etiopathogenesis and implications for management. Adv Ther. 2016:33(11):1921-46.

13. Lespasio MJ, Sultan AA, Piuzzi NS, Khlopas A, Husni ME, Muschler GF, et al. Hip osteoarthritis: a primer. Perm J. 2018;22:17-084. https://doi.org/10.7812/ TPP/17-084

14. Austin PC, Allignol A, Fine JP. The number of primary events per variable affects estimation of the subdistribution hazard competing risks model. J Clin Epidemiol. 2017:83:75-84.

15. Miller LE, Gondusky JS, Bhattacharyya S, Kamath AF, Boettner F, Wright J. Does surgical approach affect outcomes in Total hip arthroplasty through 90 days of follow-up? A systematic review with meta-analysis. J Arthroplast. 2018:33(4):1296-302.

16. Angerame MR, Fehring TK, Masonis JL, Mason JB, Odum SM, Springer BD. Early failure of primary Total hip arthroplasty: is surgical approach a risk factor? J Arthroplast. 2018;33(6):1780-5.

17. Rodriguez JA, Deshmukh AJ, Rathod PA, Greiz ML, Deshmane PP, Hepinstall MS, et al. Does the direct anterior approach in THA offer faster rehabilitation and comparable safety to the posterior approach? Clin Orthop Relat Res. 2014;472(2):455-63.

18. Higgins BT, Barlow DR, Heagerty NE, Lin TJ. Anterior vs. posterior approach for total hip arthroplasty, a systematic review and meta-analysis. J Arthroplast. 2015;30(3):419-34.

19. Graves SC, Dropkin BM, Keeney BJ, Lurie JD, Tomek IM. Does surgical approach affect patient-reported function after primary THA? Clin Orthop Relat Res. 2016;474(4):971-81.

20. AOANJJR. National Joint Replacement Registry, Annual Report 20182018 1801-2019; (09-01-2019). Available from: https://aoanjrr.sahmri.com/ documents/10180/576950/Hip\%2C\%20Knee\%20\%26\%20Shoulder\%2 OArthroplasty.

21. NRJ. 15th Annual Report 2018, National Joint Registry for England, Wales, Northern Ireland and the Isle of Man2018 10-01-2019]; (10-01-2019). Available from: http://www.njrreports.org.uk/Portals/0/PDFdownloads/ NJR\%2015th\%20Annual\%20Report\%202018.pdf.

22. Tsikandylakis G, Mohaddes M, Cnudde P, Eskelinen A, Karrholm J, Rolfson O. Head size in primary total hip arthroplasty. EFORT Open Rev. 2018;3(5):225-31.

23. Girard J. Femoral head diameter considerations for primary total hip arthroplasty. Orthop Traumatol Surg Res. 2015;101(1 Suppl):S25-9.

24. Hailer NP, Weiss RJ, Stark A, Karrholm J. The risk of revision due to dislocation after total hip arthroplasty depends on surgical approach, femoral head size, sex, and primary diagnosis. An analysis of 78,098 operations in the Swedish hip arthroplasty register. Acta Orthop. 2012;83(5):442-8.

25. Zijlstra WP, De Hartog B, Van Steenbergen LN, Scheurs BW, Nelissen R. Effect of femoral head size and surgical approach on risk of revision for dislocation after total hip arthroplasty. Acta Orthop. 2017;88(4):395-401.

26. Barrett WP, Turner SE, Leopold JP. Prospective randomized study of direct anterior vs postero-lateral approach for total hip arthroplasty. J Arthroplast. 2013;28(9):1634-8.

27. Drummond J, Tran P, Fary C. Metal-on-metal hip arthroplasty: a review of adverse reactions and patient management. J Funct Biomater. 2015;6(3): 486-99.

28. Lindgren JV, Gordon M, Wretenberg P, Karrholm J, Garellick G. Validation of reoperations due to infection in the Swedish hip arthroplasty register. BMC Musculoskelet Disord. 2014;15:384.

29. de Steiger RN, Lorimer M, Solomon M. What is the learning curve for the anterior approach for total hip arthroplasty? Clin Orthop Relat Res. 2015; 473(12):3860-6.

30. Hartford JM, Bellino MJ. The learning curve for the direct anterior approach for total hip arthroplasty: a single surgeon's first 500 cases. Hip Int. 2017; 27(5):483-8.

31. Bryant D, Havey TC, Roberts R, Guyatt G. How many patients? How many limbs? Analysis of patients or limbs in the orthopaedic literature: a systematic review. J Bone Joint Surg Am. 2006;88(1):41-5.

32. Park MS, Kim SJ, Chung CY, Choi IH, Lee SH, Lee KM. Statistical consideration for bilateral cases in orthopaedic research. J Bone Joint Surg Am. 2010;92(8):1732-7.

33. Robertsson $\mathrm{O}$, Ranstam J. No bias of ignored bilaterality when analysing the revision risk of knee prostheses: analysis of a population based sample of 44,590 patients with 55,298 knee prostheses from the national Swedish knee arthroplasty register. BMC Musculoskelet Disord. 2003;4:1.

\section{Publisher's Note}

Springer Nature remains neutral with regard to jurisdictional claims in published maps and institutional affiliations.
Ready to submit your research? Choose BMC and benefit from:

- fast, convenient online submission

- thorough peer review by experienced researchers in your field

- rapid publication on acceptance

- support for research data, including large and complex data types

- gold Open Access which fosters wider collaboration and increased citations

- maximum visibility for your research: over $100 \mathrm{M}$ website views per year

At BMC, research is always in progress.

Learn more biomedcentral.com/submissions 